\title{
Evaluation of the Bond Strength and Marginal Seal of Indirect Restorations of Composites Bonded with Preheating Resin
}

\author{
Manuel Salvador Urcuyo Alvarado ${ }^{1}$ Diana María Escobar García² Amaury de Jesús Pozos Guillén² \\ Juan Carlos Flores Arriaga² Gabriel Fernando Romo Ramírez ${ }^{2}$ Marine Ortiz Magdaleno² \\ ${ }^{1}$ Department of the Specialty in Aesthetic, Cosmetic, Restorative, \\ and Implantological Dentistry, Faculty of Stomatology, \\ Autonomous University of San Luis Potosí, San Luis Potosí, México \\ 2Laboratory of Basic Science, Faculty of Dentistry, Autonomous \\ University of San Luis Potosí, San Luis Potosí, México

\begin{abstract}
Address for correspondence Marine Ortiz Magdaleno, DDS, MSc, Dentistry, Faculty of Stomatology, Autonomous University of San Luis
\end{abstract} \\ $\mathrm{PhD}$, Specialty in Aesthetic, Cosmetic, Restorative, and Implantological \\ Potosí, Avenue Dr. Manuel Nava \#2, Zona Universitaria, 78290, S.L.P. México \\ (e-mail: marine.ortiz@uaslp.mx).
}

Eur ] Dent:2020;14:644-650

\section{Abstract \\ Keywords \\ - preheated resin \\ - marginal sealing \\ - indirect restorations \\ - microtensile bond strength \\ - adhesive interface}

Objective Preheated resins (PR) are considered a cementing agent option for indirect adhesive restorations of composite inlays and onlays. The objective of this in vitro study was to evaluate the marginal sealing, adhesive interface, and microtensile bond strength of indirect adhesive restorations of composites in terms of dentin cemented with PR.

Materials and Methods Standardized Class II preparations were performed on 30 extracted human premolars, impressions were taken, and indirect composite restorations were manufactured. In total, 15 restorations were cemented with PR (ENA HRi, SYNCA), and 15 restorations were cemented with self-adhesive resinous cement (RC) (Relyx U200, 3M ESPE), followed by a thermocycling regime. After that, these were segmented sagittally and longitudinally to evaluate the marginal sealing and the adhesive interface with scanning electron microscopy and confocal microscopy. Microtensile bond strength was assessed with a mechanical device (TA. XT Plus C, Stable Micro System).

Statistical analysis Statistical analysis was conducted using the two-sample Student's $t$-test.

Results The results showed that there is no statistically significant difference in the degree of microfiltration using PR or RC; however, microtensile bond strength is greater when the restoration is cemented with $R C\left(278.75 \mathrm{~N} / \mathrm{cm}^{3}\right)$ than with PR $\left(144.49 \mathrm{~N} / \mathrm{cm}^{3}\right)$, and better adjustment and sealing were observed for composite restorations with PR.

Conclusion PR comprise an alternative cementing agent for indirect composite restorations in Class II cavities in premolars.

\section{Introduction}

Advances in adhesive dentistry have increased the applications of partial adhesive aesthetic restorations of conservative and aesthetic inlays and onlays. The purpose of these restorations is to preserve and protect the intact structure and healthy remnant of the tooth..$^{1,2}$ They are made with ceramic materials that exhibit beneficial mechanical properties and composites that possess an elastic module similar to that of dentin and that can be manufactured with a technique directly in the mouth or indirectly by manually working with a model stone or with computer-aided design/ computer-aided manufacturing. ${ }^{3}$ 
Adhesive restorations are continuously subjected to stress and occlusal forces, and composites are materials that best distribute the loads in Class II cavities, ${ }^{4,5}$ in that these types of cavities compromise the interproximal walls of the teeth. In addition, these types of cavities are more prone than other types to poor marginal proximal adaptation between the restorative material and the dentary substrate due to limitations in visibility and access to the cavity. The design of the cavity and the contraction caused by polymerization of the composites are considered the main risk factors causing the formation of marginal gaps; $6^{7}$ it has been reported that marginal retention loss is one of the main causes of restoration failure. ${ }^{8}$ In this type of clinical situation, the indirect technique is recommended because it provides better visualization for marginal adaptation of the material, easy manipulation of the restoration, and allows adjustment of the interproximal contacts. ${ }^{9,10}$

The choice of cementing material for indirect adhesive restoration depends on the thickness of the film formed by the cement, wear resistance, marginal sealing, and photocuring capacity. Indirect adhesive restorations are often bonded with RC that have been developed for use without the need for a bonding agent; their low solubility and viscosity provide a clinically acceptable cement film thickness and have been shown to have better mechanical properties than conventional cements. ${ }^{11,12}$

An alternative cementation material is PR because by increasing its temperature to between $55^{\circ}$ and $60^{\circ} \mathrm{C}$, its viscosity is reduced. Additionally, its fluidity is reduced by the increased free radical mobility, which facilitates better adaptation to the walls of the cavity, compared with that of conventional cementation materials. PR cementation also results in superior marginal adaptation, reducing microfiltration, and therefore increasing the durability of the restorations, ${ }^{13}$ which also facilitates the cementing of restorations with a relatively low polymerization contraction. However, the use of the PR technique is considered sensitive due to the strict temperature control required, but it should not cause irreversible damage to the pulp tissue. ${ }^{14}$

Marginal integrity and the cementing agent are key factors that determine the success of an adhesive restoration; the ideal cement should not wear out or have cracks. Studies have focused on the use of PR for conservative dentistry, but there is not sufficient information concerning its use as a cementing agent. According to the literature, there is little scientific evidence of the effect of PR as cementing agents for indirect partial adhesive restorations of composites. The objective of this in vitro experimental study was to evaluate the marginal sealing and adhesive interface with scanning electron microscopy (SEM) and Confocal laser microscopy (CLSM) of indirect partial adhesive restorations of composites to dentin in Class II cavities of premolars cemented with RC (Relyx U200; 3M ESPE, Minnesota, United States) and PR (ENA HRi; SYNCA, New York, United States). The bond strength of indirect restorations to dentin was evaluated with the XT Plus C Texture Analyzer (Stable Micro System, United Kingdom). The null hypothesis of this study lies in that there is no difference in marginal sealing, adhesive interface, or the bond strength of indirect composite adhesive restorations utilizing RC and PR.

\section{Materials and Methods}

\section{Sample Collection}

A total of 30 upper and lower premolars were collected from patients who visited the specialty clinic of the Orthodontics Department of the Universidad Autónoma de San Luis Potosí with indications for extraction by orthodontic treatment, following the acquisition of informed and signed consent. The inclusion criteria were upper and lower premolars without destruction of their clinical crown and root, cavities, fractures, or the presence of previous restorations. All of the specimens were stored in a hydrating medium, and scaling was performed to remove any plaque, calculus, or periodontal tissues. Subsequently, these were washed with saline solution and kept in thymol at $4^{\circ} \mathrm{C}$ until use, but for no longer than 3 months.

\section{Cavity Preparation}

A single operator created Class II cavities (mesio-occlusal, $4 \mathrm{~mm}$ in distal-mesial width, $4 \mathrm{~mm}$ in the vestibule-palatine plane or buccolingually, and $5 \mathrm{~mm}$ in depth); the measurements were performed with a periodontal probe, and the cavities were created with a high-speed turbine (KaVo Kerr; California, United States) with a rounded coarse-grain diamond extreme cutter (3131 Azdent Baistra; Henan, China) and with profuse irrigation. The cutter was changed after every five cavities. The teeth were mounted on an acrylic arch to obtain an impression with an impression tray with holes (Rim Lock; Dentsply, PA, United States) and with the two-step technique with a heavy- and light-addition silicon (Silagum; DMG, Germany), following the manufacturer's instructions. After 1 hour, the impressions were filled with cast type IV Elite Rock (Zhermack; RO, Italy) to prepare cast portions of $22 \mathrm{~g} / 100 \mathrm{~mL}$.

\section{Preparation and Cementation of the Restorations}

A separating layer (MDC, California, United States) was placed into the cavities of the cast models, and the 30 indirect restorations were manufactured with UD2 color dentin composite (ENA HRi, SYNCA) employing the oblique incremental technique with layers of $2 \mathrm{~mm}$ thick. Each layer was photopolymerized for 20 seconds at an intensity of $1,200 \mathrm{~mW} / \mathrm{cm}^{2}$ (Bluephase $\mathrm{N}$; Ivoclar Vivadent, New York, United States). The samples were randomly distributed into two experimental groups corresponding to the cementing material (-Table 1): group A, 15 restorations cemented with RC (resinous cement) (Relyx U200, 3M ESPE), and group B, 15 composite restorations cemented with PR color UD2 (ENA HRi, SYNCA). All procedures were performed according to manufacturers' instructions (-Tables 2 and 3). The restorations were polished with flexible Sof-Lex finishing and polishing discs (3M ESPE) and were subjected to a thermocycling regimen of 500 cycles with an exposure time of $30 \mathrm{sec}$ onds at $4^{\circ}, 37^{\circ}$, and $57^{\circ} \mathrm{C}$ to simulate the environment of an oral cavity. 
Table 1 Brand and batch number of the preheated resin and dual-cured cementing system

\begin{tabular}{|l|l|l|l|}
\hline Trade name & Manufacturer & Type of cement & Batch \\
\hline Relyx U200 & $\begin{array}{l}\text { 3M ESPE, St. Paul, Minnesota, United States } \\
\text { USA }\end{array}$ & Self-adhesive resinous cement & 4636189 \\
\hline ENA HRi & ENA HRi, SYNCA, New York, United States & Preheated resin & 2017003475 \\
\hline
\end{tabular}

Table 2 Preparation of the composite restoration surface prior to cementing

\begin{tabular}{|l|l|}
\hline $\begin{array}{l}\text { Trade } \\
\text { name }\end{array}$ & Procedure in composite restoration \\
\hline $\begin{array}{l}\text { Relyx } \\
\text { U200 }\end{array}$ & $\begin{array}{l}\text { Place the restoration in the ultrasound for } 5 \text { minutes } \\
\text { and apply two layers of Silane (Ultradent, Utah, United } \\
\text { States) for } 3 \text { minutes. }\end{array}$ \\
\hline ENA & $\begin{array}{l}\text { Place the restoration in the ultrasound for } 5 \text { minutes } \\
\text { and apply two layers of Silane (Ultradent) for } 3 \text { minutes } \\
\text { and add two layers of adhesive (Single Bond Universal, } \\
\text { 3M ESPE) without photocuring. }\end{array}$ \\
\hline
\end{tabular}

Table 3 Cementation procedure in the dental substrate

\begin{tabular}{|l|l|}
\hline $\begin{array}{l}\text { Trade } \\
\text { name }\end{array}$ & Procedure in the dental substrate \\
\hline U200 & $\begin{array}{l}\text { Selective engraving in the enamel with orthophos- } \\
\text { phoric acid (Scotchbond Universal Adhesive, 3M ESPE) } \\
\text { for } 20 \text { seconds wash with a water spray for } 40 \text { seconds } \\
\text { and dry for } 5 \text { seconds without fully drying the sample. } \\
\text { Impregnate the cavity with the cement and settle the } \\
\text { restoration. Remove the excess before photocuring. }\end{array}$ \\
\hline ENA & $\begin{array}{l}\text { Selective engraving in the enamel with orthophos- } \\
\text { phoric acid (Scotchbond Universal Adhesive, 3M ESPE) } \\
\text { for } 20 \text { seconds wash with a water spray for 40 seconds } \\
\text { and dry for 5 seconds without fully drying the sample. } \\
\text { Rub two layers of adhesive (Single Bond Universal, 3M } \\
\text { ESPE) for } 20 \text { seconds and photocure for } 20 \text { seconds. } \\
\text { Impregnate the cavity with preheated resins that was } \\
\text { previously in an engine (HRi) at a temperature of } 39^{\circ} \text { to } \\
55^{\circ} \mathrm{C} \text { for } 60 \text { minutes and apply it to the cavity floor. }\end{array}$ \\
\hline
\end{tabular}

\section{Evaluation of Marginal Sealed and Adhesive Interfaces}

The first cut was transversal on the occlusal face, followed by a sectional cut in the wall of the proximal restoration, and finally an internal longitudinal cut was made in the middle part of the restoration ( - Fig. 1). The width of the specimens was $1.5 \mathrm{~mm}$, and the cuts were made with a diamond disc with two lights IsoMet Wafering Blades 15 LC (Buehler, Germany). The specimens were polished with 600-, 800-, and 1,000-grit sandpaper to obtain a smooth surface and were thoroughly dehydrated at intervals of 30 minutes in alcohol at concentrations of $25,40,50,75,80,90$, and $100 \%$, and were coated with 15 to $20 \mathrm{~nm}$ gold particles to be observed by SEM (JEOL JSM-6510; JEOL, Massachusetts, United States).

\section{Evaluation of the Microfiltration}

The teeth were covered with two layers of nail varnish on the entire surface, with the exception of the occlusal and mesial faces of the axial faces of the cavities of the specimens, leaving $1 \mathrm{~mm}$ free around the sealant edges. The teeth were incubated in a fluorescent solution of rhodamine B

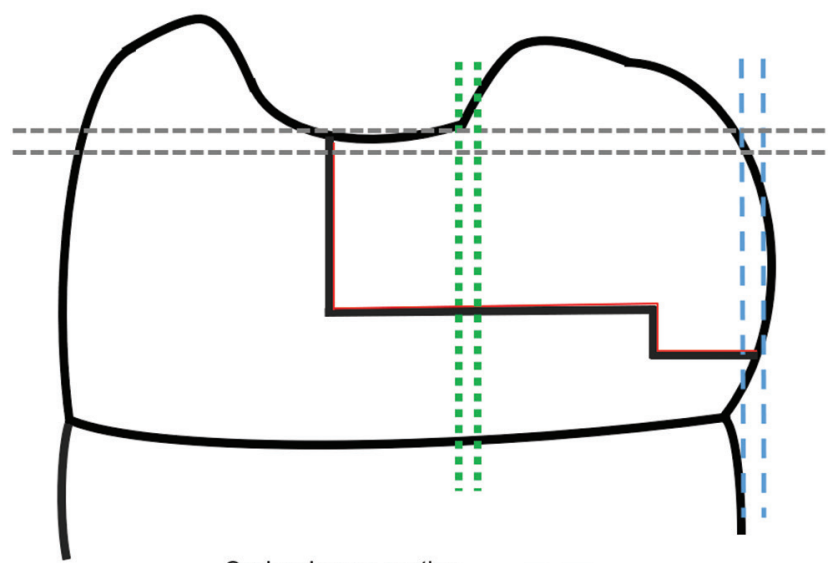

Occlusal cross section
External longitudinal section
Internal longitudinal section
Dental cement

Fig. 1 Schematic view of the transversal occlusal cross-section, external longitudinal sections of the proximal wall of the restoration, and the internal longitudinal section of the restoration.

(0.02 mg/200 mL sterile distilled water; Sigma-Aldrich, St. Louis, Missouri, United States) for 24 hours followed by a vigorous washing step to remove the excess rhodamine, and were allowed to dry for 72 hours. Subsequently, a $1.5-\mathrm{mm}$ thick proximal case-level cut was made with a two-light diamond disc IsoMet Wafering Blades $15 \mathrm{LC}$ (Buehler) to observe the microfiltration of the fluorescent agent with CLSM (Leica Model DMI4000B, Germany). LASAF (Leica, Germany) was used to obtain images with a $\times 40$ objective; five measurements were made on each image of the rhodamine penetration into the walls and on the floor of the cavity. All samples were observed by the same examiner, and measurements were randomly repeated in a blinded manner.

\section{Microtensile Bond Strength Test}

The restorations cemented with RC (resinous cement) and PR were cut crosswise into $1.5-\mathrm{mm}$ discs to be mounted onto a microtensile device (TA. XT Plus C; Stable Micro System), which was utilized to evaluate the composite restorations attached with RC or PR. The parameters employed were a speed of $3 \mathrm{~mm} / \mathrm{second}$ with a force of $5 \mathrm{~g}$ for stretching to evaluate the microtensile bond strength.

\section{Statistical Analysis}

Statistical analysis, consisting of a Mann-Whitney $U$ test with $95 \%$ confidence intervals was performed with Minitab version 17 statistical software. 


\section{Results}

Evaluation of Marginal Sealing and Adhesive Interfaces The descriptive analysis of the SEM micrograph of a longitudinal cut of the indirect composite restorations cemented with RC revealed the presence of gaps in the tooth-restoration junction interface on the cavity floor, and no intimate sealing of the restoration was observed between the RC and dentin at an $\times 80$ magnification ( - Fig. 2 A). At a magnification of $\times 1,500$, there was no smear layer, indicating adhesive failure by a clear separation and the formation of a gap between the dentin and the restoration ( - Figs. $\mathbf{2 B}$ and $\mathbf{2 C}$ ). In restorations cemented with $P R$, a narrower interface was observed along the walls and the floor of the cavity, a thin layer of PR cement was observed with some short gaps of separation toward the dentin, and resinous tags of the penetration of the PR into the dental substrate were observed ( - Fig. 2D). At a magnification of $\times 1,500$, the presence of permeable dentin tubules and the formation of a hybrid layer was observed, although there were minor partial adhesive failures. The hybrid layer in this group was characterized by its regularity and its high degree of continuity ( - Figs. 2E and F).

In the transverse cuts of the occlusal faces of the surface, the cavity edge-both in the composite restorations cemented with RC and those with PR-was observed to have marginal gaps very similar to those of the longitudinal specimens. In the restorations cemented with RC, longer distance gaps between the dentin and the composite were

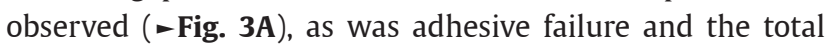
absence of a hybrid layer where a separation of the dentin and cement was clearly identified ( $\boldsymbol{- \text { Fig. }}$ 3B). In the case of cemented restorations with PR, there was a close union of the interface between the dentin and the composite ( - Fig. $\mathbf{3 C}$ ). At a magnification of $\times 1,500$, the presence of a smear layer was observed, and the hybrid layer was continuous and homogeneous throughout the adhesive interface, demonstrating a better adhesion process ( - Fig. 3D).

In the microfiltration measurements of rhodamine in dentin, an average value of $84.4 \mu \mathrm{m}$ was obtained in the restorations cemented with RC; for PR, the value was $47.7 \mu \mathrm{m}$ and no statistically significant difference was determined (-Fig. 4A). In the images obtained with CLSM, an increase in the microfiltration of rhodamine on the floor of the cavities was observed compared with the axial walls where RC was used ( $\mathbf{- F i g}$. 5A vestibular, 5B cavity floor, 5C face palatine), while for restorations cemented with PR, although greater microfiltration was not observed, the penetration was
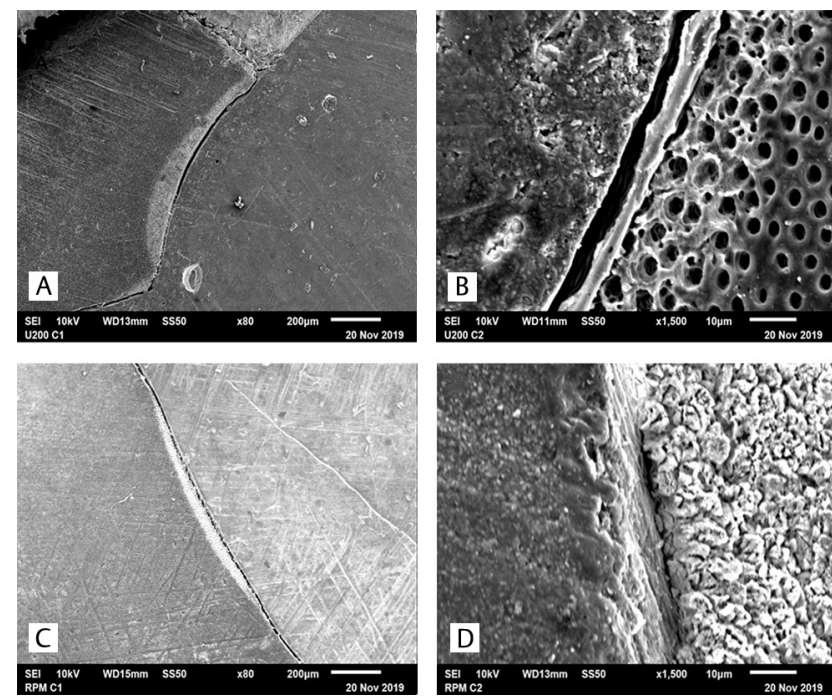

Fig. 3 Representative scanning electron microscopy micrographs of the marginal sealing in the cross-sections of the restorations of indirect resins attached with resinous cement at $\times 80(\mathbf{A})$ and the adhesive interface at $\times 1,500(B)$, with the preheated resins cementing agent at a magnification of $\times 80(\mathbf{C})$, and the adhesive interface at $\times 1,500$ (D).
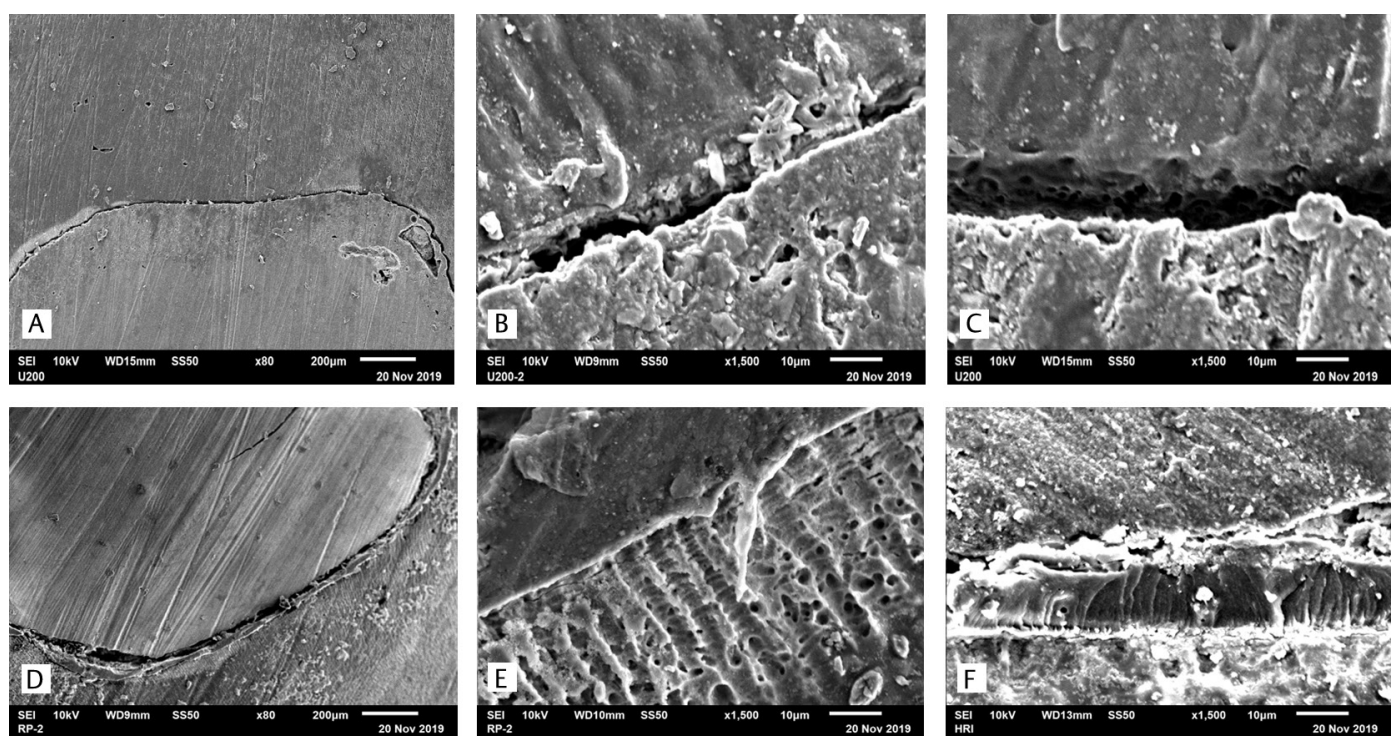

Fig. 2 Scanning electron micrographs of the longitudinal cut of the seal of the indirect restorations of a composite attached with RC at $\times 80(\mathbf{A})$ and at high magnification, $\times 1,500(\mathbf{B}, \mathbf{C})$ and cemented with preheated resins at $\times 80(\mathbf{D})$ and at $\times 1,500(\mathbf{E}, \mathbf{F})$. 

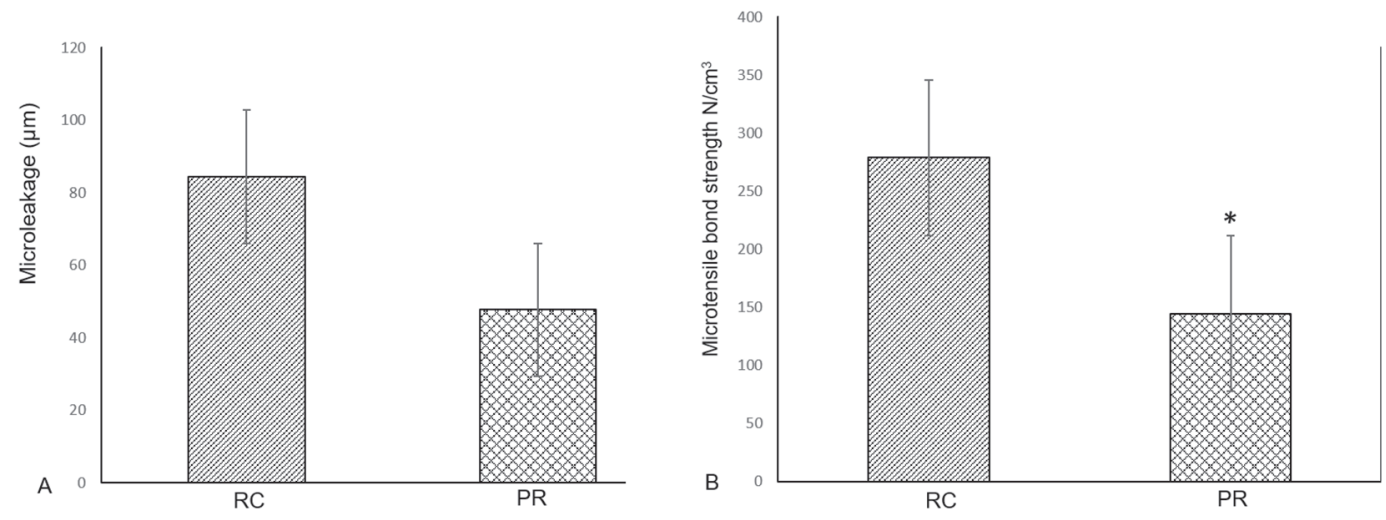

Fig. 4 Microleakage results of the values of the penetration of rhodamine in the marginal mismatch in the dentin-resin layer in the vestibular, palatine walls, and the floor of the Class II cavity (A), and the comparation of the values obtained from the microtensile bond strength of indirect resin restorations with preheated resins and RC (resinous cement). ${ }^{*}$ Indicates significant differences between both groups $(p<0.05)(\mathbf{B})$.
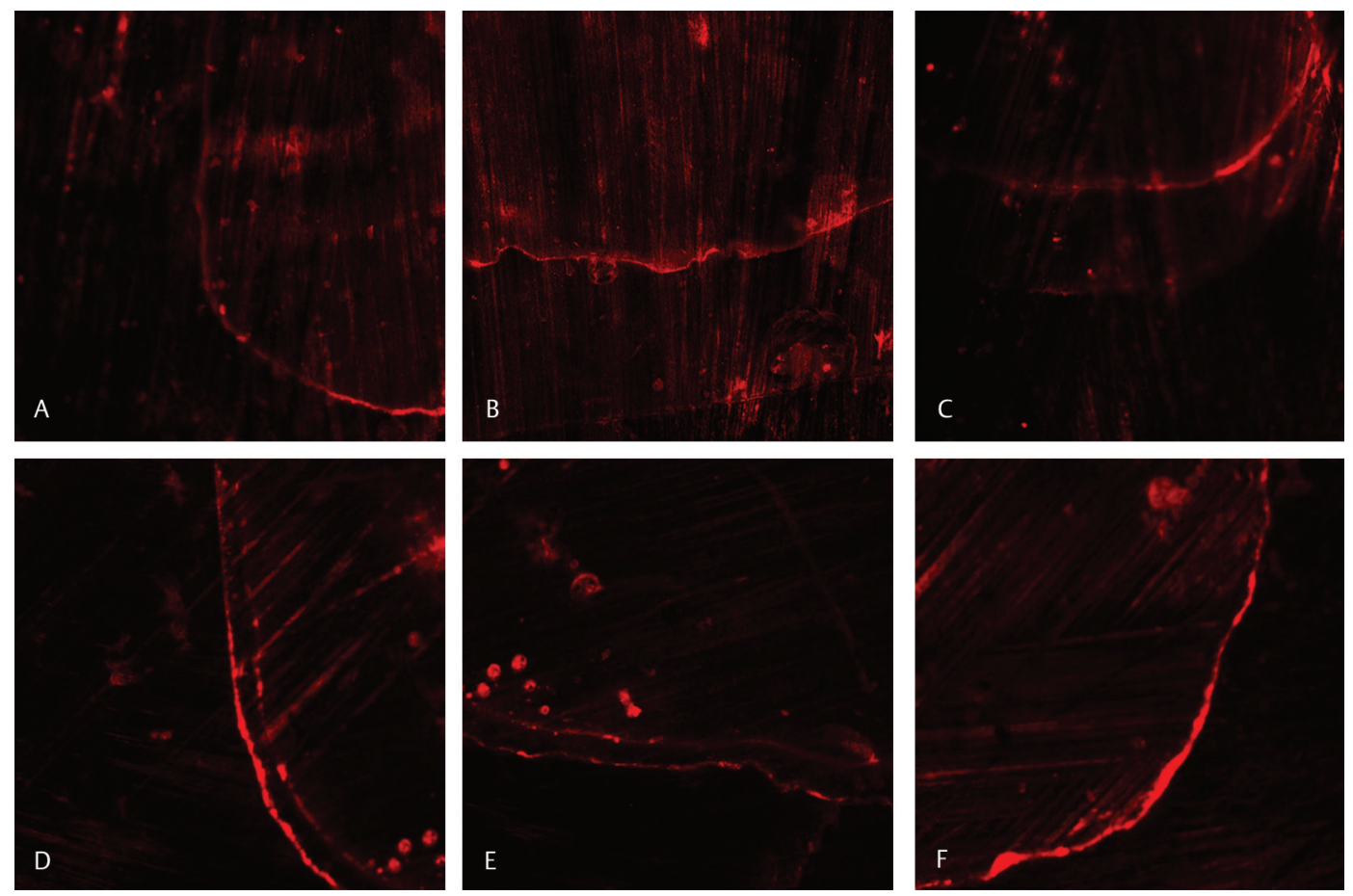

Fig. 5 Images obtained with confocal microscopy of the penetration of rhodamine in restorations cemented with resinous cement in the vestibular wall (A), cavity floor (B), and palatine wall (C), with PR in the vestibular wall (D), cavity floor (E), and palatine wall (F).

limited in the marginal mismatch space, where there was no marginal seal ( - Fig. 5D vestibular wall, 5E cavity floor, and 5F palatine wall).

\section{Microtensile Bond Strength Test}

Microtensile bond-strength values were lower in the restorations cemented with PR $\left(144.49 \mathrm{~N} / \mathrm{cm}^{3}\right)$ and higher in those cemented with RC $\left(278.75 \mathrm{~N} / \mathrm{cm}^{3}\right)$, with a statistically significant difference between the two groups $(p<0.05$; - Fig. 4B).

\section{Discussion}

This study aimed to show that the use of PR as a cementing agent of indirect composite restorations in Class II cavities of premolars improves marginal sealing and therefore decreases microfiltration. Upon analyzing the results obtained in this study, it was observed that microfiltration was not eliminated in either of the two cements evaluated. The results showed that there was no significant difference in microfiltration in Class II cavities using PR or RC (resinous cement); however, the values obtained from microfiltration 
were lower for PR than for RC (resinous cement), while the micrographs obtained with SEM revealed better sealing and adaptation utilizing PR. The composite restorations probably settled better with PR due to the degree of fluidity of the material, improving the adaptation and thus the marginal sealing.

Studies have shown that RC (resinous cement) exhibited lower values of microfiltration than conventional cementing systems in both enamel and in dentin,, ${ }^{15,16}$ and insufficient scientific evidence has been reported on the effect of the use of PR on the marginal sealing and adhesive force of a composite to dentin restorations. Wagner et a ${ }^{17}$ demonstrated significantly less microleakage at the cervical margin of Class II restorations with preheated composites, while Goulart et al ${ }^{18}$ concluded that preheating composite resin for luting procedures may not improve the seal.

In indirect restorations of ceramics or in the composite values of marginal discrepancy ranging from 48 to $219 \mu \mathrm{m}$, it is recommended that the marginal adaptation of inlays should be less than $100 \mu \mathrm{m}^{19}$; in our study, values less than $100 \mu \mathrm{m}$ were obtained with an average value of $47.7 \mu \mathrm{m}$ with PR and 8 of $4.4 \mu \mathrm{m}$ for RC (resinous cement). It is noteworthy that the marginal discrepancy values are enhanced with the viscosity of cement and excess cement depending on the geometry of the cavity, and that there is a possibility that the marginal discrepancy values may be increased after the cementing protocol, the latter attributed to the increase of hydraulic pressure of the resin luting cement. ${ }^{20}$

On the other hand, the temperature of the materials has been shown to be a factor at room temperature or higher than the temperature of the human body ${ }^{21}$; preheating the resins to $60^{\circ} \mathrm{C}$ increases the conversion of monomers by increasing molecular mobility. Compounds with higher conversion have greater crosslinking and the free space of the polymers is reduced, improving their mechanical properties..$^{22-24}$ In this study, the PR was preheated to $55^{\circ} \mathrm{C}$, a factor against the elapsed time of the isothermal condition to be placed in the syringe to inject the material, causing a temperature reduction to $50 \%$ after 2 minutes. ${ }^{25}$ The RC (resinous cement) evaluated in this study was employed at room temperature, and a temperature reduction was not possible. The best temperature to cement the materials remains controversial, as studies have shown that cements at different temperatures did not exert significant effects on the marginal gap widths of the restorations, ${ }^{26}$ and that preheating the light-curing only composites allows the materials to reach an optimal degree of conversion. ${ }^{27}$ That is, the temperature does not influence the formation of the marginal gap, but it does exert an influence the fluidity of the material. It is important to note that the temperature increase should not affect the pulp tissue, and previous findings have demonstrated that an increase in the composite resin temperature to between $54^{\circ}$ and $60^{\circ} \mathrm{C}$ does not significantly change the intrapulpar temperatures. ${ }^{28}$

Effective adhesion in enamel and dentin comprises an associated factor in the microtensile adhesion strength and in reducing the marginal microfiltration of indirect composite restorations. Studies have shown that the cervical enamel/ dentin and composite resin interface are more vulnerable to microleakage. ${ }^{28}$ In this study, analysis of the bond interface was observed in the SEM, and the PR group was observed to possess a hybrid layer after following the adhesion protocol. For RC (resinous cement), no prior treatment of the adhesive system is needed, and they also have the option of being utilized with conventional engraving. The results observed in the micrographs in this study revealed that the hybrid layer did not form, and adhesive failure is evident by the formation of gaps in the seal. In this study, the microtensile adhesion force of indirect composite restorations using PR as a cementing agent was lower than that of RC (resinous cement), possibly due to the composition and properties of RC (resinous cement) compared with PR. However, there remains controversy concerning what type of cement system has the best adhesion values in the cementation of partial adhesive composite restorations. Hepburn et $\mathrm{a}^{29}$ recommend PR as a cementing agent, despite that the adhesive cementing systems clinically demonstrate an acceptable marginal discrepancy. In the case of veneer cementation, the use of preheated resinous cements has not shown greater volumetric polymerization shrinkage than the veneer cements; contrariwise, the film's thickness has been less than that of the cement veneer when using the cementing agents of preheated fluid resins. ${ }^{30}$

Indirect adhesive restorations in resin are an economical option compared with other materials and are indicated when a proximal wall is missing, as in Class II cavities. The technique and the cementing agent are responsible for the volumetric contraction by polymerization and the thickness of the cement film, ${ }^{27}$ and the composite selection impacts its response to preheating and the viscosity and thickness of the film..$^{29}$ Marginal gaps cause microfiltration, which is the main cause of the failure of a restorative treatment. ${ }^{30}$ It is essential not to risk the formation of marginal gaps due to an inappropriate combination of the restorative material with the technique and cementing material. From a clinical perspective, the results of the present study show that PR is a luting agent for restorations of inlay-type composites in Class II cavities, and the possible advantages of its clinical use include the ease of removing excess material due to its fluidity in the walls of the cavity. Future studies will be required to evaluate the biological or clinical behavior in vivo of PR in the oral cavity. ${ }^{31,32}$

The limitations of this in vitro model are related to the differences between room temperature and mouth temperature, a discrepancy of $40 \mu \mathrm{m}$ has been reported in the impression material at room temperature compared with that at mouth temperature by impression polymerization, ${ }^{33}$ as well as the decrease in the temperature of the PR after removal from the heating device and the time elapsed for placing the PR into the in vitro model compared with the mouth temperature. ${ }^{34}$ These conditions must be taken into account when the results obtained in this study are interpreted under clinical conditions.

\section{Conclusion}

PR are a cementing agent option for indirect resin restorations in Class II cavities in premolars; however, a limitation of this in vitro study is that it found no statistically significant difference 
in the degree of microfiltration using PR or RC, but in spite of that, better sealing and adaptation of restorations was observed using PR. The microtensile adhesion force between dentin and resin restoration is increased when cemented with a RC.

\section{Funding}

This work was supported by a grant to M.S.U.A. as a CONACYT fellow (grant number: 6118114/574819).

\section{Conflict of interest}

None declared.

\section{References}

1 Höland W, Schweiger M, Watzke R, Peschke A, Kappert H. Ceramics as biomaterials for dental restoration. Expert Rev Med Devices 2008;5(6):729-745

2 Moszner N, Klapdohr S. Nanotechnology for dental composites. Int J Nanotechnol 2004;1:130-156

3 Van Noort R, Introduction to Dental Materials Section II. London: Mosby; 1994:89-105

$4 \mathrm{Kim} \mathrm{KH}$, Ong JL, Okuno O. The effect of filler loading and morphology on the mechanical properties of contemporary composites. J Prosthet Dent 2002;87(6):642-649

5 Ausiello P, Rengo S, Davidson CL, Watts DC. Stress distributions in adhesively cemented ceramic and resin-composite Class II inlay restorations: a 3D-FEA study. Dent Mater 2004;20(9):862-872

6 Giachetti L, Scaminaci Russo D, Bambi C, Grandini R. A review of polymerization shrinkage stress: current techniques for posterior direct resin restorations. J Contemp Dent Pract 2006;7(4):79-88

7 Ferracane JL, Mitchem JC. Relationship between composite contraction stress and leakage in Class V cavities. Am J Dent 2003;16(4):239-243

8 Naeselius K, Arnelund CF, Molin MK. Clinical evaluation of all-ceramic onlays: a 4-year retrospective study. Int J Prosthodont 2008;21(1):40-44

9 Poskus LT, Latempa AM, Chagas MA, Silva EM, Leal MP, Guimarães JG. Influence of post-cure treatments on hardness and marginal adaptation of composite resin inlay restorations: an in vitro study. J Appl Oral Sci 2009;17(6):617-622

10 Ozakar-Ilday N, Zorba YO, Yildiz M, Erdem V, Seven N, Demirbuga S. Three-year clinical performance of two indirect composite inlays compared to direct composite restorations. Med Oral Patol Oral Cir Bucal 2013;18(3):e521-e528

11 Peutzfeldt A, Asmussen E. A comparison of accuracy in seating and gap formation for three inlay/onlay techniques. Oper Dent 1990;15(4):129-135

12 Touati B, Aidan N. Second generation laboratory composite resins for indirect restorations. J Esthet Dent 1997;9(3):108-118

13 Deb S, Di Silvio L, Mackler HE, Millar BJ. Pre-warming of dental composites. Dent Mater 2011;27(4):e51-e59

14 Fróes-Salgado NR, Silva LM, Kawano Y, Francci C, Reis A, Loguercio AD. Composite pre-heating: effects on marginal adaptation, degree of conversion and mechanical properties. Dent Mater 2010;26(9):908-914

15 Piwowarczyk A, Lauer HC, Sorensen JA. Microleakage of various cementing agents for full cast crowns. Dent Mater 2005;21(5):445-453

16 Fabianelli A, Goracci C, Bertelli E, Monticelli F, Grandini S, Ferrari M. In vitro evaluation of wall-to-wall adaptation of a self-adhesive resin cement used for luting gold and ceramic inlays. J Adhes Dent 2005;7(1):33-40

17 Wagner WC, Aksu MN, Neme AM, Linger JB, Pink FE, Walker S. Effect of pre-heating resin composite on restoration microleakage. Oper Dent 2008;33(1):72-78

18 Goulart M, Borges Veleda B, Damin D, Bovi Ambrosano GM, Coelho de Souza FH, Erhardt MCG. Preheated composite resin used as a luting agent for indirect restorations: effects on bond strength and resin-dentin interfaces. Int J Esthet Dent 2018;13(1):86-97

19 Gladys S, Van Meerbeek B, Inokoshi S, et al. Clinical and semiquantitative marginal analysis of four tooth-coloured inlay systems at 3 years. J Dent 1995;23(6):329-338

20 Sakrana AA. In vitro evaluation of the marginal and internal discrepancies of different esthetic restorations. J Appl Oral Sci 2013;21(6):575-580

21 Lovell LG, Lu H, Elliott JE, Stansbury JW, Bowman CN. The effect of cure rate on the mechanical properties of dental resins. Dent Mater 2001;17(6):504-511

22 Daronch M, Rueggeberg FA, De Goes MF, Giudici R. Monomer conversion of pre-heated composite. J Dent Res 2005;84(7):663-667

23 Daronch M, Rueggeberg FA, De Goes MF, Giudici R. Polymerization kinetics of pre-heated composite. J Dent Res 2006;85(1):38-43

24 Asmussen E, Peutzfeldt A. Influence of pulse-delay curing on softening of polymer structures. J Dent Res 2001;80(6):1570-1573

25 Daronch M, Rueggeberg FA, Moss L, de Goes MF. Clinically relevant issues related to preheating composites. J Esthet Restor Dent 2006;18(6):340-350, discussion 351

26 Morais A, Santos AR, Giannini M, Reis AF, Rodrigues JA, Arrais CA. Effect of pre-heated dual-cured resin cements on the bond strength of indirect restorations to dentin. Braz Oral Res 2012;26(2):170-176

27 Acquaviva PA, Cerutti F, Adami G, et al. Degree of conversion of three composite materials employed in the adhesive cementation of indirect restorations: a micro-Raman analysis. J Dent 2009;37(8):610-615

28 Daronch M, Rueggeberg FA, Hall G. De Goes MF. Effect of composite temperature on in vitro intrapulpal temperature rise. Dent Mater 2007;23(10):1283-1288

29 Hepburn BA. Composite resin inlays: general considerations. Rev Asoc Odontol Argent 2004;98:253-264

30 Zavattini A, Mancini M, Higginson J, Foschi F, Pasquantonio G, Mangani F. Micro-computed tomography evaluation of microleakage of Class II composite restorations: an in vitro study. Eur J Dent 2018;12(3):369-374

31 Rodrigues Junior SA, Pin LF, Machado G, Della Bona A, Demarco FF. Influence of different restorative techniques on marginal seal of class II composite restorations. J Appl Oral Sci 2010;18(1):37-43

32 Tezvergil A, Lassila LVJ, Vallittu PK. The shear bond strength of bidirectional and random-oriented fibre-reinforced composite to tooth structure. J Dent 2005;33(6):509-516

33 Kim K-M, Lee J-S, Kim K-N, Shin S-W. Dimensional changes of dental impression materials by thermal changes. J Biomed Mater Res 2001;58(3):217-220

34 Lohbauer U, Zinelis S, Rahiotis C, Petschelt A, Eliades G. The effect of resin composite pre-heating on monomer conversion and polymerization shrinkage. Dent Mater 2009;25(4):514-519 